\title{
Review of Ecotherapy: Healing With Nature in Mind
}

\section{Submitted by Lisa Lynch}

Antioch University Seattle, Seattle, Washington.

\section{Abstract}

This is a four-part review of the new book Ecotherapy: Healing With Nature in Mind edited by Linda Buzzell and Craig Chalquist and published by Sierra Club Books. Bringing together four different perspectives offers an opportunity for a dimensional review that is representative of the many practices this book is intended to inform. Lisa Lynch and Thomas Doherty, as teachers of ecopsychology, review the text at both the undergraduate and graduate psychology level. They look at the book as an important representation of the ever-evolving field of ecopsychology and suggest ways the text could be stronger, and emphasize the ways in which it makes a necessary contribution to their teaching. Martin Jordan reviews the book from across the Atlantic in England and suggests that the book could have attended to a more inclusive perspective. As a scholar and practitioner he is able to emphasize certain essays and how they make a contribution to the work he is doing. Sandra Newes reviews Ecotherapy from the point of view as a professionally trained Clinical Psychologist who is grateful to have found these many techniques that serve to support in incorporating a relationship and connection to nature into her psychotherapeutic practice. We chose this format in order to provide a round table of voices that each contribute a unique and important perspective. It is intended to give the reader a beginning at which to evaluate the text on their own, glean what is useful, and perhaps contribute in some way to the ever-evolving form of ecopsychology and ecotherapy.

\section{Introduction}

e invited four readers to review the newly published Ecotherapy: Healing With Nature in Mind by Sierra Club Books. Thomas Doherty, Sandra Newes, and Martin Jordan; are clinically trained practitioners of psychotherapy and offer their insights into the contribution this book has made to their practice and the exploration of this newly defined practice of ecotherapy. Lisa Lynch and Thomas Doherty review this book from an academic perspective, evaluating the book as a teaching tool to be used in the classroom. It was important to invite these many perspectives in creating this review. What this book has to offer is of great value to the practitioners and teachers in ecopsychology and we wanted to share with you a diverse, sometimes complimentary, sometimes contradictory reading of this text.

\section{Lisa Lynch \\ Coordinator of Integrated Studies in Psychology Ecopsychology Concentration, Associate Faculty, School of Applied Psychology, Counseling and Family Therapy, Antioch University Seattle, Washington.}

Fourteen years ago Ecopsychology: Restoring the Earth, Healing the Mind by Theodore Roszak, Mary Gomes, and Allen Kanner was published. That book served to gather together a number of perspectives, ideas, and practical illustrations around the newly born movement of ecopsychology. As an educator and scholar in the field I have waited breathlessly for a new edition, the next wave of ideas and perspectives that would serve to evolve ecopsychology and lift it onto the next level of understanding and integration into western education and psychotherapeutic practices. This new collection of essays, Ecotherapy: Healing With Nature in Mind, is an effort to illustrate what the authors call an applied ecopsychology. In some ways, this text exemplifies rather than solves one of the central issues we have struggled with in ecopsychology these many years. The practice of ecopsychology embraces a vastness that spans many disciplines and modalities. From shamanism to gardening; dream analysis to wilderness therapy; ecopsychology and now ecotherapy seems to scramble for a definition. That is not to say that every one of these practices can be considered as working from an informed ecopsychological perspective. But, 
BOOK REVIEW: ECOTHERAPY: HEALING WITH NATURE IN MIND

what is that? How is dream analysis ecopsychology and not depth psychology? And, is applied ecopsychology merely a new stack of therapeutic techniques, utilizing nature as a tool for individual healing? In his essay, Psyche as big as the Earth, Theodore Roszak attempts to show us the depth of what he imagined an applied ecopsychology would look like, "Many therapists seem content to tinker, adjust, and above all prescribe; it is all their clients seem to expect. Going deeper takes longer and hurts more" (p. 36). Is it the role of psychotherapy to help people feel better about what is going on in their lives and the world around them, or to address, as Joanna Macy says, "a dysfunctional and pathological notion of the self" that "derives from a mistaken understanding of our place in the order of things" (p. 241)? These quotes refer the reader back to the early days of ecopsychology, where the practice of contemporary psychotherapy was called into question and challenged to broaden its definitions of self and the techniques of adaptation.

This collection of very short essays is a multidimensional look at the practices and insights of many practitioners. As a text book it does not offer the kind of depth I was hoping for and I am left wondering if the book would have served our needs better if there were fewer contributors and longer essays. Also, it seems the editors gleaned from a mostly Euro-American, Northern California base of authors. I do get criticism from my classes for not offering readings that are multicultural and come from a more environmental justice and indigenous perspective. It is true that there are mostly Euro-Americans writing and thinking about ecopsychology, but it would serve to enrich and expand the appeal of ecopsychology to tend the possibility of being inclusive and draw from a more diverse base of contributors.

What is true about the role of ecopsychology and ecotherapy is that its best application will serve humanity and our relationship to the potential threats and impending changes of a warming earth. We are heading into a vastly unknown and dangerous future. What the impacts of inevitable climate change will bring to us physically and psychologically are unknown. As Richard Heinberg says in his essay, "In the decades ahead we will be going through hell. That is an awful thing to contemplate, but the only alternative to accepting the facts is to live in denial until the reality is inescapable and our room for maneuvering is even more restricted than it has already become" (p. 202). I honor this book and the tenacity of the editors for gathering many essays that can help those of us working in the classrooms and therapy offices, some tools, some comfort, and courage to "go deeper" and serve the earth and those who suffer with her through the inevitable changes that we all know are coming.

\section{Martin Jordan \\ School of Applied Social Sciences, University of Brighton, East Sussex, United Kingdom.}

I approached the review of this book as both a practitioner of ecotherapy and an academic researching the area of relationships with nature and mental health. As a psychotherapist using ecotherapy in my practice, I found the definition of ecotherapy as applied ecopsychology very helpful. Ecotherapy is positioned as a new form of psychotherapy that addresses the vital role of nature in human health and well-being and also addresses the human nature relationship. The book presents an important polemic in that ecotherapy is situated as a critique of aspects of main stream therapy, which has tended to ignore the environmental crisis as having anything to do with psychotherapy.

The book is divided into themed areas, which allow the reader to see the scope and practice of ecotherapy. For those looking for tips on practice, chapters by George W. Burns and John Scull are particularly useful. One of the strengths of the book is that ecotherapy is situated within communities and in the work of the transition movement; hence the reader will find chapters by Bill McKibben and Richard Heinberg acknowledging the emotional basis of the shift to ecologically sustainable communities and economies.

Reading as an academic, I enjoyed the chapters by Andy Fisher, who positions ecopsychology as a critical social theory. He articulates the importance of praxis, that is, the relationship of theory to practice, and the importance of ecotherapy as essential to reconnecting people to the healing power of nature. The chapter by Theodore Roszak focuses on the dangers of moralizing about particular forms of destructive activities. Roszak states that rather than being an "inconvenient truth" the environmental crisis "paralyzing truth" and we need to acknowledge that even with the facts people would not always act in environmentally responsible ways because their lives are so difficult to manage. Ecotherapy, argues Roszak, has an important role in promoting therapeutic relationships with nature and developing "a psyche as big as the earth."

My only criticism of the book is its overwhelmingly transatlantic feel. There are a few exceptions to this and the version of ecotherapy promoted by a recent report here in the United Kingdom (MIND, 2007) is omitted. This report has done a lot to promote the role of contact and activities in nature and the positive effects on those experiencing distress within mental health services in the United Kingdom. It has even led to the 


\section{LYNCH}

development of a psychologist post-specializing in ecotherapy within the National Health Service. Although the MIND report does not draw from the ideas of deep ecology, transpersonal or depth psychology, which a lot of ecotherapy ideas and practice seem to, it has none the less been very important here in the United Kingdom.

Overall, I have enjoyed reading the book and thinking about the application of its ideas to my practice. When a client I was assessing recently for post trauma stress syndrome (PTSD) after a road traffic accident talked about the importance of birds and bird song to her recovery, having ecotherapy in my mind even though my role was purely as psychologist, made the conversation we subsequently had about the importance of birds and the natural world all the more possible and valid.

\section{Sandra Newes}

Clear View Psychological Services, Asheville, North Carolina.

I am delighted to have found this ground-breaking work! As a traditionally trained Clinical Psychologist, I have long felt the lack of emphases on cultural integration, somatic awareness, and interpersonal/ecological systems to be essential missing links in the development of holistic perspectives on lasting human growth and change. Based on my own transformative experiences in connection with the natural world, I have been personally committed to exploring the integration of nature-based experiential processes into an ongoing course of psychotherapy. Unfortunately, there have been few professional resources in these areas and those that do exist have historically been disparate, lacking in theoretical grounding, and have limited applied utility. Accessing this largely disconnected professional community has also been quite challenging.

As part of my own efforts to integrate clinical theory into adventure and wilderness therapy, I have been active in several professional organizations, and served in several leadership positions. I offer a variety of training and mentorship services in this field, and have continued to explore resources that expand the existing literature in the wilderness/adventure therapy fields; which tends to primarily emphasize the concepts of risk, challenge, and task accomplishment. It is difficult to find anything written from either clinical or integrative perspectives, and few resources exist that provide "how to" guidance for trained clinicians. I have also been concerned about the lack of theoretical grounding and exploration of the applied clinical utility for particular issues; along with the often poorly articulated links to evidence-based practices in psychotherapy. In addition, the majority of the existing literature overlooks the intentional use of nature-based activities to teach such foundational skills as self-reflection, emotion regulation, identity formation, independent and interdependent self-conceptions, and sensory/somatic awareness.

This book begins this process, and I am excited to have been given the rare treat of exploring a work that so greatly expanded my thinking about this complex integration in such a well-written and sophisticated fashion. Never before have I encountered a resource so directly relevant to applying the concepts and techniques of Ecotherapy into existing practice, and this is the first work of its kind to begin to ground the utilization of nature-based activities within established clinical theory and method. At the same time, it does an outstanding job of encouraging the integration of culture, environmentalism, and spiritual perspectives into this same integrative process; putting forth a collective viewpoint that, over time, may well gently challenge the established tenets of accepted mental health treatment.

I am also excited about the potential for this book to open the door to this type of exploration. Drawing from a diverse range of perspectives, it provides a foundation upon which to focus the ongoing evolution of increasingly sophisticated theory and practice in this area. By concurrently offering an exploration of contexts in which Ecotherapy can be applied, a more complete understanding of how to do so, and some basic activities to start with; this book will be an invaluable resource for professionals interested in exploring this developing field. Opportunities are created for future works to build upon this, allowing for increasingly well developed examinations of these linkages.

\section{Thomas Joseph Doherty}

Sustainable Self, LLC, Lewis and Clark Graduate School of Education and Counseling, Portland, Oregon.

A quotation by the writer Kurt Vonnegut hangs in my office: "Still in all, why bother? Here's my answer: Many people need desperately to receive this message: 'I feel and think much as you do, care about many of the things you care about, although most people don't care about them. You are not alone.'” In many ways, this sums up the value of the edited volume Ecotherapy from Sierra Club books. It also suggests some of the work's weaknesses. I approach this review from a perspective as a psychotherapist, 
BOOK REVIEW: ECOTHERAPY: HEALING WITH NATURE IN MIND

educator, and scholar of environmental perspectives in psychology, including ecopsychology.

Ecotherapy is an important milestone, a notable entry into a sparse literature. Those new to this way of thinking may find these well-written essays to be validating, inspiring, and possibly life changing. Those familiar with ecopsychology will recognize familiar voices and witness an evolution in the field with an increased recognition of research evidence and integration of modalities such as horticultural, equine, and movement therapy. The volume gathers knowledge that has been circulating among practitioners for a number of years including Burns' natureguided therapy with couples, Edwards and Buzzell's description of the "Waking up Syndrome," and Scull's nature-based practice guidelines. There is an accessible description of Fisher's philosophically sophisticated radical ecopsychology practice. Readers are introduced to important voices such as Rust and Chalquist. Contemporary issues are addressed with Heinberg's description of the psychological ramifications of peak phenomena (e.g., "Peak Oil”) and Anderson's critique of the corporate system. Effective popularizes of psychology research are included with McKibben's discussion of positive psychology and Louv's description of restorative natural environments and children's health.

As in previous ecopsychology literature, Ecotherapy illustrates the value of theory and practices drawn from outside of mainstream academic research and psychotherapy practice including archetypal, humanistic, somatic, critical, and transpersonal perspectives. However, as someone who deeply believes in the promise of ecopsychology, and values appropriate psychotherapy integration, scientific pluralism, and not only "speaking to the choir," Ecotherapy leaves much to be desired and contains elements that may hinder a proliferation of ecologically-informed mental health practices.

Robinson's contribution is emblematic of some problems in the volume and I will briefly focus on it given its prominent place as lead essay. While voicing entirely valid critiques of consumer society and profit-driven mental health care, Robinson also stereotypes the majority of psychotherapy practitioners as mechanistic-thinking tools of the [US] managed care industry. His essay perpetuates a cultural critique that too easily conflates psychopathology and competing environmental values-in this case anthropocentric values and norms. This ignores important aspects of cultural, racial, ethnic, geographical, and political diversity and is hardly the stuff of rapport and coalition building. This is a very important point. While ecotherapists would seek to destigmatize and depathologize connection and love for the Earth, should we be content to stigmatize and pathologize others' disconnection?

Robinson's contention that with intersubjectivity with naturean I-thou relationship-neurosis "melts away" (p. 28) is certainly enticing. Yet, his offhand dismissal of the majority of his colleagues and exclusive privileging of humanistic and depth approaches runs counter to findings in psychotherapy outcome research that recognize the importance of the goodness-of-fit between clients' needs and therapists' offerings. His partisan approach invites the critique that ecotherapists are pushing an environmental agenda. We cannot be satisfied with this. Ecotherapy practitioners and teachers can augment the material in Ecotherapy with other resources from environmental, conservation, and health psychology, and clinical and counseling approaches as appropriate.

The passion and partisanship of the writers in Ecotherapy would benefit from the balance of a critical and even skeptical perspective that opens the discussion to what may be problematic or contradictory within ecotherapy theory and practice. In reading Ecotherapy, one has the feeling of stepping into a psychotherapy or recovery group and I believe the honesty and vulnerability of the writing demands respectful and validating attention. I wish for a conversation that safely contains the assumptions of the group while also questioning those assumptions.

\section{Summ ary}

These reviews all offer a very interesting and compelling perspective to both this text and the continuing evolution of the practice of ecopsychology. It is encouraging to see that so many have come to embrace ecopsychology as a point of view in their practice and their teaching. What would be next for the scholars and writers to explore would be to go back to the some of the early sources in ecopsychology, and reconnect with the essential spirit and theory that ecopsychology emerged from. It would be helpful to clarify and illuminate the complexity and beauty of the deeper thoughts and theories that ecopsychological practices can draw from. Perhaps it would be useful to create a clear definition of what the differences and similarities are between what is being called applied ecopsychology and ecotherapy. For ourselves as teachers, practitioners, and writers and for our students, clients, and communities we can and must hold onto the roots and tend the soil of this very important emerging shift in our social and ecological consciousness. Scholarly contributions that are rigorous and careful will serve to evolve these very important ideas, practices and perspectives of ecopsychology into a neces- 


\section{LYNCH}

sary and powerful presence in our society, our culture, and our essential relationship with the earth.

\section{REFERENCES}

Buzzell, L., \&t Chalquist, C. (Eds.). (2009). Ecotherapy: Healing with nature in mind. San Francisco, CA: Sierra Club Books.

Heinberg, R. (2009). The psychology of peak oil and climate change. In C. Chalquist, and L. Buzzell (Eds.), Ecotherapy: Healing with nature in mind (pp. 197-204). San Francisco, CA: Sierra Club Books.

Macy, J. (2009). The greening of the self. In C. Chalquist, and L. Buzzell (Eds.), Ecotherapy: Healing with nature in mind (pp. 238-245). San Francisco, CA: Sierra Club Books.

MIND. (2007). Ecotherapy: The green agenda for mental health. London, UK: Mind.

Robinson, L. (2009). Psychotherapy as if the world mattered. In C. Chalquist, and L. Buzzell (Eds.), Ecotherapy: Healing with nature in mind (pp. 24-29). San Francisco, CA: Sierra Club Books.
Roszak, T. (2009). A psyche as big as the earth. In C. Chalquist, and L. Buzzell (Eds.), Ecotherapy: Healing with nature in mind (pp. 30-36). San Francisco, CA: Sierra Club Books.

Address correspondence to:

Dr. Lisa Lynch

School of Applied Psychology Antioch University Seattle

2326 6th Avenue Seattle, WA 98121

E-mail:1lynch@earthlink.net

Received: September 18, 2009 Accepted: September 21, 2009 